\title{
Influência da textura e mineralogia na determinação da umidade de solos utilizando micro-ondas
}

\author{
Erika Andressa Silva ${ }^{1}$ \\ Pedro Antônio Namorato Benevenute ${ }^{2}$ \\ Mariany Isabela Soares Domingues ${ }^{3}$
}

\section{RESUMO}

A umidade obtida pelo método da estufa apresenta como inconveniente o tempo necessário para sua obtenção. Como alternativa, tem sido sugerida a obtenção da umidade via forno micro-ondas. Entretanto, solos argilosos dotados de altos teores de óxidos têm apresentado comportamento peculiar, quando submetidos à radiação eletromagnética. Assim, o objetivo deste trabalho foi avaliar a utilização do forno micro-ondas na determinação da umidade de Latossolos de texturas contrastantes e variados teores de óxidos de ferro e alumínio. Foram utilizadas amostras deformadas do horizonte $\mathrm{Bw}$ de dez Latossolos. Em triplicata foram realizados ensaios para obtenção da umidade pelos métodos da estufa $\left(105^{\circ} \mathrm{C} / 24\right.$ horas) e micro-ondas. Os ensaios em micro-ondas foram efetuados com o aparelho Turntable Microwave Oven, em potência calibrada de 800 W.J.s. ${ }^{-1}$. Os dados obtidos foram submetidos ao teste de comparação de médias Tukey (5\%). Apenas 6 minutos de secagem no micro-ondas foram suficientes para obtenção de resultados semelhantes ao da estufa. Latossolos argilosos e com maiores teores óxidos de ferro e alumínio permaneceram mais úmidos. Forno de micro-ondas é um método viável por fornecer resultados confiáveis da umidade do solo com o menor tempo.

Palavras-chave: Irradiação Eletromagnética. Método da Estufa. Mineralogia do Solo.

\footnotetext{
${ }^{1}$ Graduada em Agronomia pela Universidade Federal de Lavras - UFLA. Mestra e Doutora em Ciência do Solo pela Universidade Federal de Lavras - UFLA. É professora e pesquisadora da Universidade do Estado de Minas Gerais - UEMG, Unidade Passos, MG, Brasil. E-mail: andressaerikasilva @gmail.com.

${ }^{2}$ Graduado em Agronomia pela Universidade Federal de Lavras - UFLA. Mestre e atualmente Doutorando em Ciência do Solo pela Universidade Federal de Lavras - UFLA, MG, Brasil. E-mail: benevenutepedro@gmail.com.

${ }^{3}$ Graduanda em Agronomia pela Universidade Federal de Lavras - UFLA, MG, Brasil. E-mail: mariany.domingues1@estudante.ufla.br.
} 


\title{
Influence of texture and mineralogy in determining soil moisture using microwave
}

\begin{abstract}
The moisture obtained by the greenhouse method presents the time required to obtain it as an inconvenience. As an alternative, it has been suggested to obtain moisture a microwave. However, clay soils with high levels of oxides have shown a peculiar behavior when subjected to electromagnetic radiation. Thus, aiming to speed up the process of quantification of moisture in soils, the possibility of using the microwave oven to determine the humidity of Oxisols with contrasting textures and varied levels of iron and aluminum oxides was evaluated. Deformed samples from the Bw horizon of ten Oxisols were used. In triplicate, tests were carried out to obtain moisture using the oven methods $\left(105^{\circ} \mathrm{C} / 24\right.$ hours $)$ and microwaves. The microwave tests were carried out with the Turntable Microwave Oven device, with a calibrated power of 800 W.J.s. ${ }^{-1}$. The data obtained were submitted to the Tukey means comparison test (5\%). Only 6 minutes of drying in the microwave were sufficient to obtain results similar to the greenhouse methods. Clayey Oxisols with higher levels of iron and aluminum oxides remained more moisture. Microwave oven is the most feasible method and gives reliable results for determining soil moisture content with the shortest time.
\end{abstract}

Keywords: Electromagnetic Radiation. Greenhouse Method. Soil Mineralogy.

Artigo recebido em: 23/12/2020

Aceito em: 09/04/2021 


\section{INTRODUÇÃO}

A umidade à base de massa é definida como relação entre a massa de água contida em uma amostra de solo pela massa de solo seco, sendo expressa em quilogramas de água por quilogramas de solo $\left(\mathrm{U}, \mathrm{kg} \mathrm{kg}^{-1}\right)$. Para determinação da massa seca e da massa de água, o método tradicional é a secagem em estufa, conhecido também como padrão gravimétrico, no qual a amostra é mantida com temperatura entre $105^{\circ} \mathrm{C}$ e $110^{\circ} \mathrm{C}$, até que apresente massa constante, o que significa que perdeu sua água por evaporação.

A umidade gravimétrica é a mais fácil de ser medida, envolvendo apenas mensurações de massa (SCARAMUZZA et al., 2003). E como a estrutura do solo pode ser destruída, uma vantagem do método gravimétrico de determinação da umidade é que qualquer instrumento pode ser utilizado para retirar amostras de solo, que devem ter, no mínimo, uma massa entre 10 a100 g de solo (SCARAMUZZA et al., 2003; QUINTINO et al., 2015).

Existem diversos métodos para medição de umidade do solo, cada um com suas particularidades e aplicações. Alguns parâmetros como precisão, tempo de leitura e custobenefício devem ser considerados na escolha do método a ser utilizado (FREITAS et al., 2012; QUINTINO et al., 2015). O custo de aquisição de um forno micro-ondas é inferior ao das estufas de ventilação forçada, que devem ser preferencialmente indicadas para secagem, por distribuírem de maneira uniforme o aquecimento.

O método da estufa, apesar da precisão e da vantagem em número de amostras que podem ser trabalhadas simultaneamente, tem como principal inconveniente a demora na sua realização (BUSKE et al., 2014; QUINTINO et al., 2015). E, na agricultura, o interesse é por métodos rápidos de obtenção da umidade do solo para otimizar as tomadas de decisões (QUINTINO et al., 2015). Produtores almejam conhecer a umidade do solo para gerenciar os sistemas de irrigação e drenagem, definir épocas de preparo de solo e semeadura e monitorar o tráfego de máquinas para que não ocorra compactação (BUSKE et al., 2014).

Nesse contexto, visando tornar mais ágil o processo de obtenção de umidade de solos, têm sido utilizados os fornos de micro-ondas, que têm fornecido resultados rápidos e acessíveis à realidade das propriedades agrícolas (BUSKE et al., 2014; CREMON et al., 2014; SANTOS; SILVA FILHO, 2019; TAVARES et al., 2018; VINHOLIS et al., 2008). 
Com esse método, o processo de secagem do solo ocorre a partir do emprego da radiação eletromagnética; e tem como princípio o fato da molécula de água ser um dipolo elétrico natural, que sofre rotação quando exposto a um campo eletromagnético. $\mathrm{O}$ atrito molecular resultante gera calor instantâneo, que é distribuído de maneira uniforme na amostra de solo, reduzindo a umidade (AGUILAR, 2001).

Em várias condições experimentais, solos argilosos, dotados de altos teores de ferro, têm apresentado um comportamento peculiar quando submetidos à radiação eletromagnética. Isso porque óxidos reagem de maneira diferente ao serem bombardeados por micro-ondas, com alguns óxidos com comportamento não linear de aquecimento (KOLEINI, BARANI, 2012). Enquanto as hematitas apresentam um aumento de temperatura linear, as goethitas exibem picos de aquecimento, dada a perda de água e sua transformação para uma nova composição mineralógica: hidrohematita. Portanto, pesquisas têm demonstrado que a quantidade e os tipos de óxidos presentes influenciam o processo de secagem de solos em micro-ondas, sendo que o tempo de secagem pode ser variável conforme o percentual de goethita e hematita de um solo (TAVARES et al., 2008; SANTOS; SILVA FILHO, 2019).

Por outro lado, não se tem estudos a respeito do comportamento de solos argilosos e com maiores teores óxidos de alumínio quando submetidos a processos de secagem em micro-ondas. Assim, o objetivo deste trabalho é avaliar a influência da textura, dos teores de óxidos de ferro e alumínio na obtenção da umidade de Latossolos do Cerrado por forno de micro-ondas.

\section{MATERIAL E MÉTODOS}

\subsection{Descrição dos solos e preparo das amostras para análises}

Foram utilizadas amostras deformadas do horizonte $\mathrm{Bw}$ de dez Latossolos representativos do Bioma Cerrado Brasileiro (Tabela 1), caracterizados por Severiano (2010). 
Tabela 1: Características químicas e mineralógicas das amostras de horizontes Bw de Latossolos do Bioma Cerrado Brasileiro

\begin{tabular}{llcccc}
\hline Classificação do Solo & Textura & Argila & $\mathbf{S i O}_{2}$ & $\mathbf{A l}_{2} \mathbf{O}_{3}$ & $\mathbf{F e}_{2} \mathbf{O}_{3}$ \\
Latossolo Vermelho Amarelo distrófico & franco arenoso & 152 & 24 & 67 & 38 \\
Latossolo Vermelho distrófico & franco argilo arenoso & 209 & 34 & 85 & 85 \\
Latossolo Vermelho distrófico & franco argilo arenoso & 263 & 24 & 113 & 116 \\
Latossolo Vermelho distrófico & franco argilo arenoso & 311 & 62 & 147 & 68 \\
Latossolo Vermelho distroférrico & franco argilosa & 365 & 41 & 173 & 181 \\
Latossolo Vermelho distrófico & argilo arenosa & 399 & 92 & 213 & 78 \\
\hline Latossolo Vermelho distroférrico & argiloso & 420 & 56 & 204 & 231 \\
Latossolo Vermelho distroférrico & argiloso & 490 & 90 & 179 & 298 \\
\hline Latossolo Vermelho distroférrico & argiloso & 521 & 87 & 205 & 245 \\
Latossolo Vermelho distrófico & muito argiloso & 716 & 180 & 344 & 105 \\
\hline
\end{tabular}

Fonte: Adaptado de Severiano (2010).

A partir de amostras de solos secas ao ar e passadas em peneiras de $2 \mathrm{~mm}$ realizou-se a análise granulométrica via agitação rápida (10.000 rpm) como dispersante físico; e $\mathrm{NaOH}$ $1 \mathrm{~mol} \mathrm{~L}^{-1} \mathrm{em}$ contato com a amostra durante $24 \mathrm{~h}$, como dispersante químico (EMBRAPA, 1997). Procedeu-se à quantificação das partículas de areia $(2,00-0,05 \mathrm{~mm})$, por tamisagem; de argila $(<0,002 \mathrm{~mm})$, pelo método da pipeta; e de silte $(0,05-0,002 \mathrm{~mm})$, determinada pela diferença entre o teor total da amostra de solo e os teores de areia e argila. Para caracterização química, foram determinados os conteúdos de $\mathrm{SiO}_{2}, \mathrm{Al}_{2} \mathrm{O}_{3}$ e $\mathrm{Fe}_{2} \mathrm{O}_{3}$ do extrato sulfúrico, após digestão com 9,4 $\mathrm{M} \mathrm{H}_{2} \mathrm{SO}_{4}$ (densidade = 1,47) conforme descrito em Embrapa (2006).

As amostras dos horizontes $\mathrm{Bw}$ dos 10 Latossolos foram secadas ao ar, passadas em peneira de malha $2,00 \mathrm{~mm}$ de abertura, e umedecidas com água destilada para homogeneização da umidade. O solo homogeneizado foi acondicionado em saco plástico onde permaneceu hermeticamente fechado por 24 horas. Decorrido este tempo, de cada saco foram retiradas três amostras para determinação da umidade pelo método padrão da estufa $\left(105^{\circ} \mathrm{C} / 24\right.$ horas $)$ e três amostras para determinação da umidade pelo forno de micro-ondas. Cada repetição foi composta por $10 \mathrm{~g}$ de solo.

\subsection{Determinação de umidade pelo método padrão da estufa}


Para obtenção da umidade pelo método padrão da estufa, $10 \mathrm{~g}$ de cada solo (massa de solo úmido (MU)) foram pesadas em balança de precisão. Em seguida, foram direcionadas à estufa a $105-110^{\circ} \mathrm{C}$ até que a massa constante fosse atingida, o que ocorreu em aproximadamente 24 horas. A massa constante foi registrada como a massa de solo seco (MS) e com a equação 1 , calculou-se a umidade à base de massa $\left(\mathrm{U}, \mathrm{g} \mathrm{g}^{-1}\right)$.

$$
U(\%)=\frac{M U-M S}{M S} \times 100 .
$$

\subsection{Determinação de umidade pelo método do micro-ondas}

Para obtenção da umidade do solo utilizando-se de forno micro-ondas, foi empregado um aparelho da marca Turntable Microwave Oven, modelo MO1108SST, cuja tensão de alimentação é $120 \mathrm{~V}(60 \mathrm{~Hz})$ e a frequência de micro-ondas é de $2450 \mathrm{MHz}$. Os ensaios foram efetuados com o aparelho em nível de potência calibrada de 800 W.J.s ${ }^{-1}$.

A metodologia utilizada para calibração foi a descrita em Souza et al. (2002), na qual utilizou-se um becker de polipropileno com $1000 \mathrm{ml}$ de água na temperatura de $\left(25^{\circ} \mathrm{C}\right)$, que foi colocado no micro-ondas na potência desejada por dois minutos. Decorrido esse tempo, o Becker com a água foi retirado do micro-ondas e, após 30 segundos de agitação da água com bastão de vidro, mediu-se a temperatura final. Esse procedimento foi realizado três vezes na potência de $100 \%$. Com a temperatura média inicial $\left(25^{\circ} \mathrm{C}\right)$ e final $\left(47,9^{\circ} \mathrm{C}\right)$ calculou-se a potência real do aparelho com auxílio da equação 2:

$$
P=35\left(T_{f}-T_{i}\right)
$$

sendo $P$ a potência real do aparelho (W.J.s $\left.{ }^{-1}\right), T_{f}$ a temperatura final e $T_{i}$ a temperatura inicial ambas em ${ }^{\circ} \mathrm{C}$.

Inicialmente, amostras de solo acondicionadas em cadinhos de porcelana foram submetidas a um tempo de 120 segundos no forno de micro-ondas. Em seguida, os cadinhos foram retirados, aguardou-se o resfriamento em dessecador e fez-se a pesagem em balança eletrônica com precisão de 0,01g. Este procedimento foi repetido de 120 em 120 segundos, até o alcance de 360 segundos (TAVARES et al., 2008). 


\subsection{Análises estatísticas}

O experimento foi montado em delineamento inteiramente casualizado com 3 repetições x 2 métodos (estufa e micro-ondas) x 10 solos, totalizando 60 amostras. Os valores de umidade obtidos pelos métodos da estufa e micro-ondas foram submetidos ao teste de comparação de médias pelo teste de Tukey a 5\%, utilizando-se o programa Infoestat@.

\section{RESULTADOS E DISCUSSÃO}

Verificou-se que solos com teores de argila superiores a $365 \mathrm{~g} \mathrm{~kg}^{-1}$ permaneceram mais úmidos do que os solos com teores de argila entre $152 \mathrm{~g} \mathrm{~kg}^{-1}$ e $311 \mathrm{~g} \mathrm{~kg}^{-1}$ (Tabela 2), independentemente do método de secagem ser estufa ou micro-ondas (M-360s).

Tabela 2: Umidade (\%) determinada pelos métodos padrão da estufa e micro-ondas em dez Latossolos do Bioma Cerrado

\begin{tabular}{|c|c|c|c|c|}
\hline Solo & ----------. & --- Umida & \%) -----. & ----------- \\
\hline ( $\mathrm{g} \mathrm{kg}^{-1}$ argila) & M-120s & M-240s & M-360s & U-estufa \\
\hline 152 & $6,2 \mathrm{a}$ & $11,7 \mathrm{~b}$ & $15,0 \mathrm{bc}$ & $17,1 \mathrm{c}$ \\
\hline 209 & $3,6 \mathrm{a}$ & $7,5 b$ & $10,0 \mathrm{c}$ & $10,9 \mathrm{c}$ \\
\hline 263 & $5,5 \mathrm{a}$ & $10,3 \mathrm{ab}$ & $12,8 \mathrm{bc}$ & $16,5 \mathrm{c}$ \\
\hline 311 & $8,3 \mathrm{a}$ & $14,3 \mathrm{~b}$ & $19,2 \mathrm{bc}$ & $20,5 c$ \\
\hline 365 & $14,6 \mathrm{a}$ & $21,9 b$ & $22,3 b$ & $22,3 b$ \\
\hline 399 & $10,2 \mathrm{a}$ & $19 b$ & $27,5 \mathrm{c}$ & $24,0 \mathrm{c}$ \\
\hline 420 & $20,8 \mathrm{a}$ & $28,1 \mathrm{~b}$ & $29,5 \mathrm{c}$ & $29,0 \mathrm{c}$ \\
\hline 490 & $13,8 \mathrm{a}$ & $23,6 b$ & $25,9 c$ & $24,4 \mathrm{c}$ \\
\hline 521 & $18,0 \mathrm{a}$ & $27,0 \mathrm{~b}$ & $28,6 \mathrm{c}$ & $27,8 \mathrm{c}$ \\
\hline 716 & $16,1 \mathrm{a}$ & $26,3 b$ & $28,9 \mathrm{c}$ & $27,5 \mathrm{c}$ \\
\hline
\end{tabular}

Médias seguidas de mesma letra na linha não diferem entre si pelo teste de Tukey (5\%). M-120s, M240s, M-360s: tempo de secagem em micro-ondas, sendo respectivamente 120s, 240 e 360 segundos.

Fonte: Elaborada pelos autores (2021). 
Em micro-ondas, nos solos mais argilosos e com maiores teores de óxidos de ferro e alumínio ocorreu uma diminuição da eficiência na desidratação (Tabelas 1 e 2). Em outras palavras, o método convencional de secagem em estufa retirou mais água das amostras que as micro-ondas. Estes resultados podem ser justificados pelo fato de os óxidos causarem uma maior dissipação das micro-ondas, ocasionando uma maior deficiência no processo de movimentação dos dipolos da água presentes nos solos, que consequentemente perdem menos água (CREMON et al., 2014; SANTOS; SILVA FILHO, 2019).

Em ensaios conduzidos por Cremon et al. (2014) com amostras de Latossolo Amarelo e Latossolo Vermelho Amarelo, verificou-se que a mineralogia destes solos influenciou o seu comportamento quando submetidos à secagem em micro-ondas. Os elevados teores de oxi-hidróxido de ferro presentes nesses solos reagiram com as micro-ondas, dispersando as moléculas d'água em agitação e diminuindo a eficiência do processo de secagem.

Ademais, a correlação positiva entre umidade e teor de argila (Figura 1, Tabela 3) demonstra que a textura influenciou o processo de perda de água dos solos, por atuar diretamente na área de contato entre as partículas sólidas e a água. Nos solos mais argilosos e com maiores teores de óxidos de ferro e alumínio, a água encontra-se retida fortemente aos colóides por forças de adsorção, o que dificulta o seu processo de extração e a secagem do solo (Tabela 2).

Figura 1: Umidade do solo obtidas pelos métodos do forno micro-ondas e estufa em função do teor de argila do solo

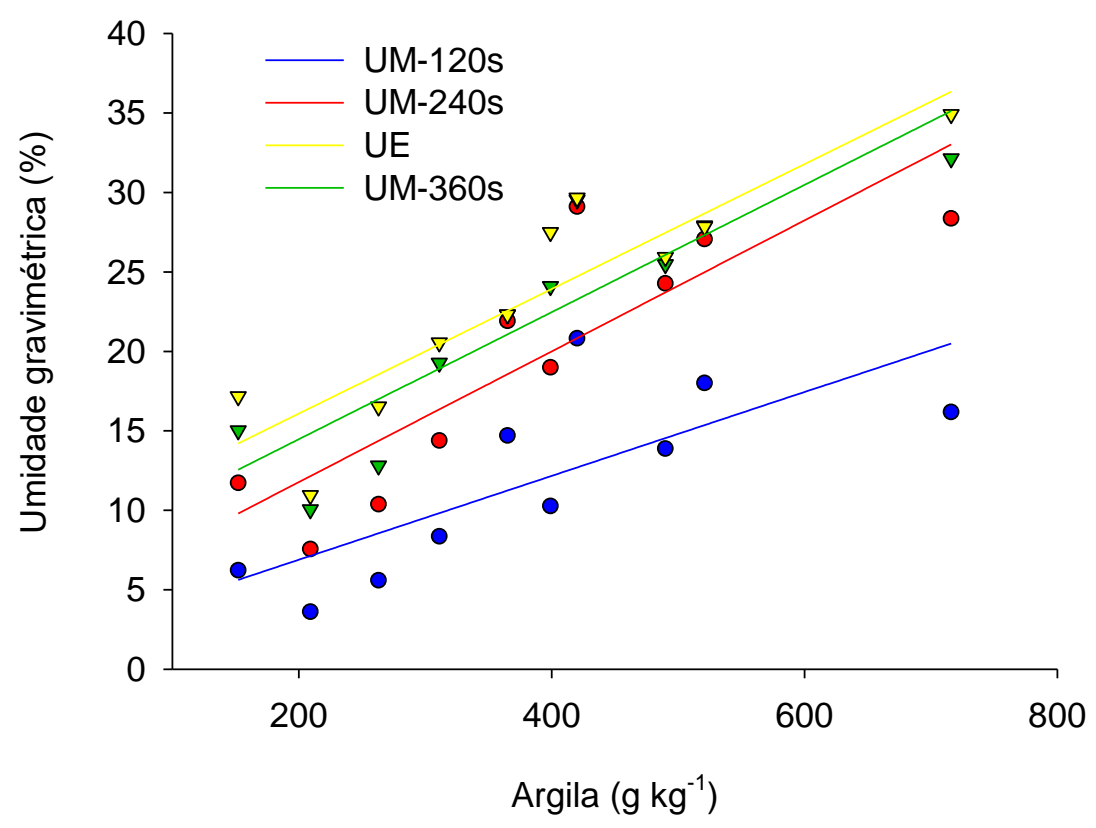

Fonte: Autoria própria (2021). 
Tabela 3: Equações de ajuste para as umidades obtidas em estufa e micro-ondas em função dos teores de argila dos Latossolos

\begin{tabular}{lll}
\multicolumn{1}{c}{ Equação de ajuste } & $\mathrm{r}^{2}$ & $\mathrm{P}$-valor \\
\hline $\mathrm{UM}-120=1,6095+0,0264$ Argila & 0,75 & $\mathrm{P}<0,05$ \\
UM-240=3,5344+ 0,0412 Argila & 0,85 & $\mathrm{P}<0,01$ \\
UM-360=6,4650+ 0,040 Argila & 0,89 & $\mathrm{P}<0,001$ \\
UE $=8,2333+0,0393$ Argila & 0,90 & $\mathrm{P}<0,001$ \\
\hline
\end{tabular}

UM-120, UM-240, UM-360: umidade em micro-ondas nos tempos de 120, 240 e 360 segundos. UE: umidade em estufa.

Fonte: Autoria própria (2021).

Nesta pesquisa, para os Latossolos estudados, o tempo de seis minutos em aparelho de micro-ondas com potência de 800 W.J.s ${ }^{-1}$ foi o mínimo necessário para se alcançar o mesmo valor de umidade obtida por secagem em estufa por 24 horas em temperatura de $\pm 105^{\circ} \mathrm{C}$ (Tabela 2).

Em seus estudos, Buske et al. (2014) e Miranda et al. (2012) observaram que um tempo de secagem de cinco minutos em micro-ondas operando com 900 Watts de potência foi suficiente tanto para solos arenosos quanto para solos argilosos, com óxidos e hidróxidos de ferro, atingirem o mesmo valor de umidade que o determinado pelo método padrão da estufa.

Na determinação da umidade por micro-ondas e estufa de um Latossolo VermelhoAmarelo do Cerrado com 20, 35 e 50\% de argila, Oliveira e Roque (2016) observaram que o tempo de secagem de 7 minutos foi suficiente para igualar a umidade dos solos em microondas àquela da estufa. Estes autores utilizaram amostras de $100 \mathrm{~g}$ de solo submetidas a potência real de $700 \mathrm{~W}$ no equipamento de micro-ondas.

Nas pesquisas de Sales et al. (2012) com solos argilosos, o tempo de cinco minutos em micro-ondas não foi suficiente para secagem de acordo com o padrão estufa, tendo sido observados melhores resultados no tempo de 10 minutos.

Verificou-se neste trabalho que se pode fazer a estimativa do teor de umidade na estufa, conhecendo-se o teor de umidade obtido no forno de micro-ondas (Figura $2 \mathrm{a}, \mathrm{b}, \mathrm{c}$ ). Maiores coeficientes de determinação $\left(\mathrm{R}^{2}=0,80\right.$ e 0,92$)$ entre os métodos foram observados nas umidades obtidas nos tempos de secagem em micro-ondas de 240 s e 360 s. 
Figura 2: Umidade do solo obtida pelo método do forno micro-ondas em função da umidade do solo obtida pelo método padrão de estufa $(n=30)$
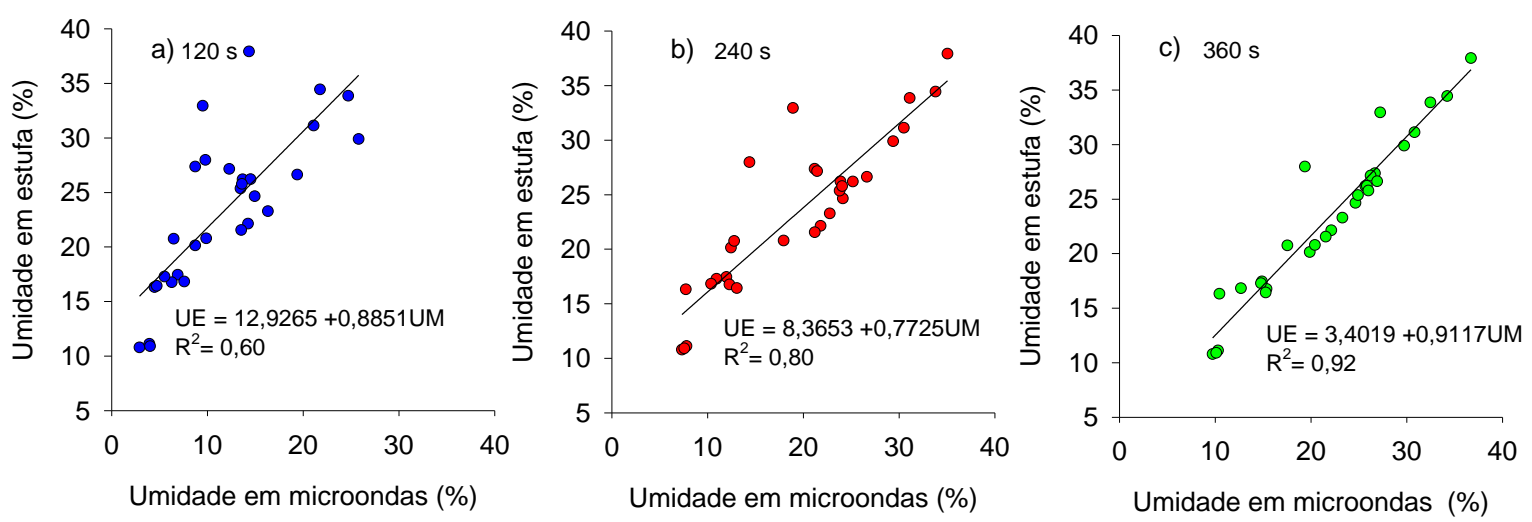

Fonte: Autoria própria (2021).

Corroborando este estudo, Tavares et al. (2008), empregando os métodos do forno de micro-ondas e da estufa para determinação da umidade de nove solos de diferentes texturas, concluíram que os resultados obtidos por ambos os métodos não diferem entre si. Fonseca et al. (2009) também concluíram em seus estudos que o forno de micro-ondas é uma metodologia confiável e que pode ser facilmente utilizada na determinação da umidade do solo.

Vinholis et al. (2008) verificaram que o uso de micro-ondas para determinação do conteúdo de água em solo pode otimizar tomadas de decisão em atividades de irrigação, por permitir a obtenção de dados confiáveis de umidade em menor tempo, quando comparado ao método padrão de estufa.

Em suma, a partir dos resultados obtidos neste trabalho, verificou-se que micro-ondas é um método de fácil manuseio, rápido e eficiente para a determinação de umidade em solos.

\section{CONCLUSÃO}

Nas condições experimentais de realização deste trabalho, com amostras de $10 \mathrm{~g}$ e forno de micro-ondas operacionalizando na potência calibrada de 800 W.J.s ${ }^{-1}$, foram necessários apenas 6 minutos de secagem para igualar a umidade do solo em micro-ondas à da estufa. 
Independentemente de o método empregado para secagem ser estufa ou micro-ondas, Latossolos dotados de maiores teores de argila e óxidos de ferro e alumínio permaneceram com maiores umidades.

\section{REFERÊNCIAS}

AGUILAR, J. A. G. Procesamiento de materiales por medio de microondas em la FIME. Ingenierías, v. 4, p. 32-39, 2001.

BUSKE, T.; ROBAINA, A.; PEITER, M.; TORRES, R.; ROSSO, R.; BRAGA, F. Determinação da umidade do solo por diferentes fontes de aquecimento. Revista Irriga - UNESP. Botucatu, v. 19, n. 2, p. 315-324, abr./jun. 2014.

CREMOM, C.; LONGO, L.; MAPELI, C. N.; SILVA, L. A. M.; SILVA, W. M. Determinação da umidade de diferentes solos do Pantanal Matogrossense via microondas e método padrão. Revista Agrarian. Dourados, v. 7, n. 24, p. 280-288, 2014.

EMPRESA BRASILEIRA DE PESQUISA AGROPECUÁRIA - EMBRAPA. Centro Nacional de Pesquisa de Solos. Sistema brasileiro de classificação de solos. 2.ed. Rio de Janeiro: Ministério da Agricultura e Abastecimento, 2006. 306 p.

EMPRESA BRASILEIRA DE PESQUISA AGROPECUÁRIA - EMBRAPA. Centro Nacional de Pesquisas de Solos. Manual de métodos de análises de solo. 2.ed. Brasília: Produção de Informação, 1997. 212 p.

FONSECA, S. O. et al. Avaliação do método do forno microondas para a determinação de umidade do solo em relação ao método padrão de estufa. In: XIII Encontro Latino Americano de Iniciação Científica e IX Encontro Latino Americano de Pós-Graduação, 2009, São José dos Campos, Anais [...] São José dos Campos: UNIVAP, 2009. p. 1-4.

KOLEINI, J.; BARANI, K. Microwave heating applications in mineral processing. Intechopen. Chapter 4. 2012. Disponível em: http://dx.org/10.5772/45750.

MIRANDA, E. et al. Uso do Forno Micro-ondas na Determinação da Umidade de um Solo Franco - Siltoso. In: Workshop internacional de inovações tecnológicas na irrigação, Fortaleza, Anais [...]. Fortaleza - CE, p. 201-203, 2012.

OLIVEIRA, L. F. C.; ROQUE; C. G. Determinação da umidade do solo por micro-ondas e estufa em três texturas de um Latossolo VermelhoAmarelo do Cerrado. Revista de Agricultura Neotropical. Cassilândia-MS, v. 3, n. 4, p. 60-64, out./dez. 2016.

QUINTINO, A. C. et al. Métodos de determinação de umidade nos solos de cerrado. Enciclopédia Biosfera. Centro Científico Conhecer - Goiânia, v. 11, n. 22, p. 2202-2213, 2015. 
SALES, M. et al. Determinação da Umidade de Solo Argiloso Pelo Método do Forno Micro-ondas. In: Congresso norte e nordeste de pesquisa e inovação - Connepi 7, 2012, Palmas, Anais [...]. Palmas - TO, out. 2012.

SANTOS, S. L. M.; SILVA FILHO, E. P. Determinação da Umidade de Solo pelos Métodos Estufa e Forno Micro-ondas em Diferentes Texturas de um Latossolo Vermelho-Amarelo Sul-Amazônico. Geografia. Londrina, v. 28, n. 2, p. 41 - 60, jul. 2019.

SCARAMUZZA, J. F.; COUTO, G. E.; MARASCHIN, L. Física do solo: manual de aulas práticas. Cuiabá: FAMEV/UFMT, 2003.

SEVERIANO, E. da C. Alterações estruturais de latossolos representativos da região do cerrado e potencial de uso de solos cultivados com cana-de-açúcar. 2010. 134 p. Tese (Doutorado em Ciência do Solo) - Universidade Federal de Lavras, Lavras, 2010.

SOUZA, G. B.; NOGUEIRA, A. R. A.; RASSINI, J. B. Determinação de matéria seca e umidade em solos e plantas com o forno de micro-ondas doméstico. Circular Técnica 33, Empresa Brasileira em Pesquisa Agropecuária - EMBRAPA, São Carlos - SP, dez. 2002.

TAVARES, M. H. F.; CARDOSO, D. L.; GENTELINI, D. P.; GABRIEL FILHO, A.; EVANDRO KONOPATS, A. Uso do forno de microondas na determinação da umidade em diferentes tipos de solo. Semina: Ciências Agrárias. Londrina, v. 29, n. 3, p. 529-538, jul./set. 2008.

VINHOLIS, M. M. B.; SOUZA, G. B.; NOGUEIRA, A. R. A.; PRIMAVESI, O. Uso do micro-ondas doméstico para determinação de matéria seca e do teor de água em solos e plantas: Avaliação econômica, social e ambiental. Custos e Agronegócio on line, v. 4, n. 2, 2008. 